\title{
Percutaneous Ureteral Embolization to Manage Fistulous Bladder Cancer
}

\begin{abstract}
An 85-year-old male who had an invasive urothelial carcinoma of the urinary bladder complicated by vesicocutaneous fistula, resulting in abscess formation. The patient was managed by percutaneous abscess drainage and ureteral embolization with permanent bilateral nephrostomy. Later, the abdominal drain was removed and the patient remained nephrostomy dependent for 5 months until he died.
\end{abstract}

Keywords: Embolization, fistula, leak, nephrostomy, occlusion, plug, sandwich, ureter, urinary diversion

\section{Introduction}

Lower urinary tract fistula/leak is a devastating sequela of multiple etiologies including iatrogenic injury during gynecologic surgeries, infectious/inflammatory diseases such as diverticulitis, primary/secondary tumors, trauma, and radiation. When leak occurs, urinary diversion can serve as a temporary solution to allow for spontaneous healing. If spontaneous healing fails, surgical repair can be considered. Inoperable patients such as those with advanced disease or prior radiation can benefit from percutaneous ureteral occlusion and permanent urinary diversion to improve their quality of life. Up to $100 \%$ success rate has been documented. ${ }^{[1]}$ We report the case of an 85-year-old male who had a fungating urothelial carcinoma of the bladder fistulizing to the abdominal wall. This resulted in an abscess formation with persistent high output despite catheter drainage. We performed a permanent ureteral occlusion to control his abscess. We discuss the indication, technique, outcome, and briefly review the literature.

\section{Case Report}

An 85-year-old male known to have hypertension, coronary artery disease, and an invasive urothelial carcinoma of the bladder dome causing bilateral ureteral obstruction

This is an open access journal, and articles are distributed under the terms of the Creative Commons AttributionNonCommercial-ShareAlike 4.0 License, which allows others to remix, tweak, and build upon the work non-commercially, as long as appropriate credit is given and the new creations are licensed under the identical terms.

For reprints contact: reprints@medknow.com for which bilateral nephrostomies were placed. Computed tomography revealed a large fungating bladder mass infiltrating into the anterior abdominal wall and forming a large collection [Figure 1]. A percutaneous drain was placed in the abdominal wall collection. Four days postdrainage, persistent output of urine and fibrinous debris were noted from the drain reaching up to $100 \mathrm{ml} /$ day. Given the patient's comorbidities that preclude him from surgery, the interventional radiologist (IR) suggested palliative urinary diversion with ureteral occlusion to control the abdominal abscess and eventually remove the drain. Multidisciplinary discussion was conducted between urologist, IR, and oncologist with consensus to proceed with ureteral occlusion. Under moderate sedation, a left nephrostogram demonstrated complete distal ureteral obstruction due to tumor [Figure 2]. Therefore, no intervention was performed. communication with the bladder and the pelvic drain [Figure 2]. Therefore, a 6-Fr/55-cm Check-Flo ${ }^{\circledR}$ sheath (Cook Medical, Bloomington, IN, USA) was advanced to the distal ureter. Using a 5-Fr Kumpe catheter (Merit Medical, South Jordan, UT, USA), an 8-mm Amplatzer plug (St. Jude Medical, St. Paul, MN, USA) was deployed distally. The catheter was pulled and another 8-mm Amplatzer plug was deployed $1.5 \mathrm{~cm}$ proximal to the previous one. A safety wire was left in

How to cite this article: Justaniah Al, Khairo MA, Alfhmy A, Guzaiz NH. Percutaneous ureteral embolization to manage fistulous bladder cancer. Arab J Intervent Radiol 2018;2:90-2. A right nephrostogram demonstrated

\section{Almamoon I. Justaniah, Motaz A. Khairo, Amal Alfhmy, Noha H. Guzaiz}

Department of Medical Imaging and Intervention, King Abdullah Medical City, Makkah, Saudi Arabia

Address for correspondence: Dr. Almamoon I. Justaniah, Department of Medical Imaging and Intervention, King Abdullah Medical City, Makkah, Saudi Arabia.

E-mail:dr_justaniah@yahoo. com

Access this article online

Website: www.arabjir.com

DOI: 10.4103/AJIR.AJIR_9_18

Quick Response Code:
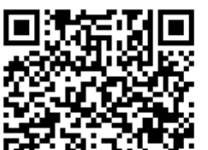

(1) 7ifas 
the dead space between the plugs. A 4-Fr Kumpe catheter was advanced over the safety wire into the dead space and primed with D5. The space was filled with $1.5 \mathrm{ml}$ of N-butyl cyanoacrylate (NBCA) (Cordis Neurovascular; Miami Lakes, FL, USA)-Lipiodol (Guerbet, Princeton, NJ, USA) (1:1 mixture) [Figure 3]. A nephrostogram was performed after $5 \mathrm{~min}$ demonstrating complete occlusion of the ureter distally [Figure 4]. A 10-Fr nephrostomy was then inserted for permanent drainage. Follow-up bilateral nephrostograms after 24 h, 2 weeks, and 4 months demonstrated continued occlusion of both ureters [Figure 5]. The abscess drain was removed after 4 weeks when the output stopped. The patient died after 5 months due to his primary disease.

\section{Discussion}

Inoperable patients with lower urinary tract fistula/leak pose a challenge to their referring physicians. If urinary diversion fails, patients can be safely treated using transrenal

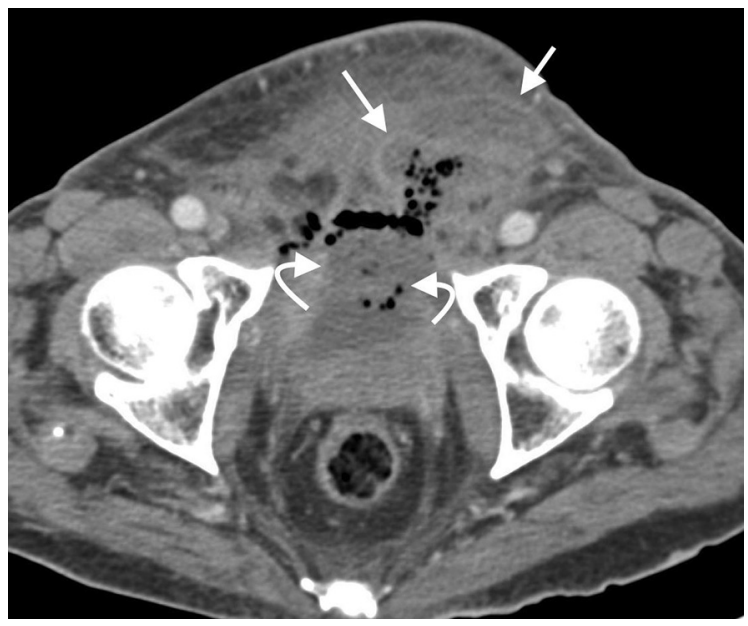

Figure 1: Axial computed tomography pelvis with intravenous contrast demonstrating interruption of the anterior bladder wall (curved arrow) with gas, fluid, and fat stranding in the abdominal wall (arrows)

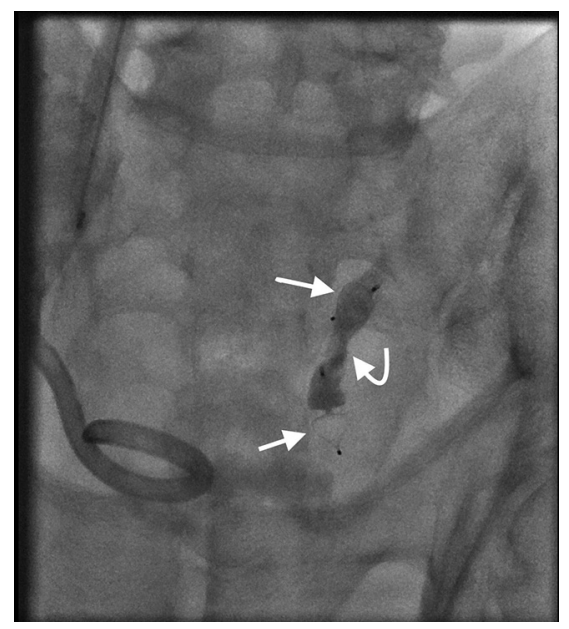

Figure 3: A single image postembolization demonstrating the radiopaque glue (arrowhead) sandwiched between the Amplatzer plugs (arrows) antegrade ureteral occlusion. Coils and Gelfoam (Upjohn, Kalamazoo, MI, USA) combination represents the most widely used technique with success rate as high as $100 \%{ }^{[1,2]}$ Other techniques with high success rates in smaller series include the "sandwich" technique described by Saad et al..$^{[3,4]}$ The "sandwich" technique is performed using an 8-12-mm Type I or Type II Amplatzer vascular plug, followed by 0.8-1.5 cc of glue (NBCA), and then by a second Amplatzer vascular plug with good results. ${ }^{[3,4]}$ We used the same technique; however, we deployed both plugs and then filled the space to prevent proximal embolization. Patency of the nephrostomy is vital to prevent recanalization. Hence, we upsized the nephrostomy to $10-\mathrm{Fr}$ and the ureter remained occluded until death.

\section{Conclusion}

Ureteral embolization is a feasible solution for inoperable patients with persistent ureteral or bladder leak/fistula.

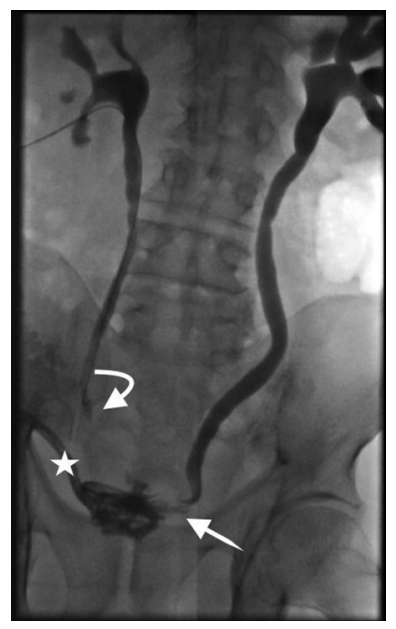

Figure 2: Percutaneous bilateral nephrostograms demonstrating obstructed left ureter (curved arrow) and patent right ureter with communication between the bladder and the abdominal wall abscess (arrow). Note the abdominal wall drain (star)

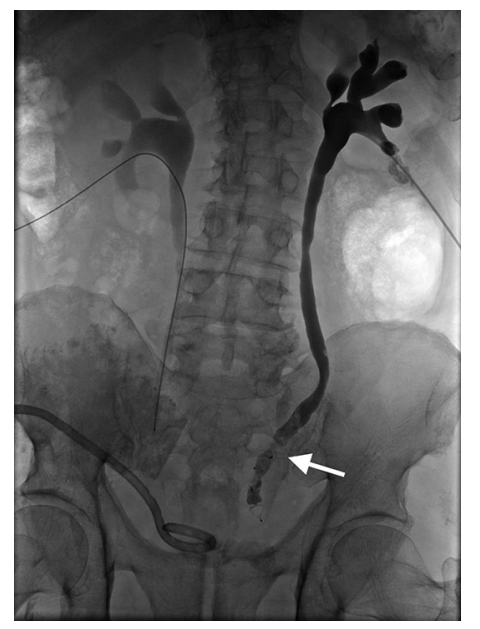

Figure 4: Percutaneous right nephrostogram postembolization demonstrating complete occlusion of the ureter (arrow) 


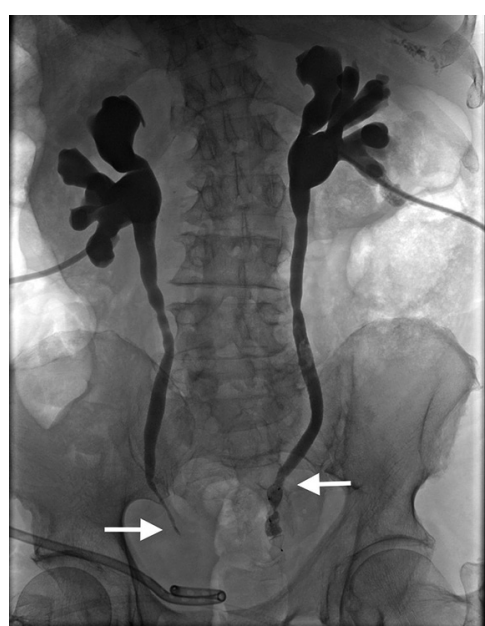

Figure 5: Two weeks postembolization bilateral nephrostograms demonstrating continued complete occlusion of both ureters (arrows)

\section{Financial support and sponsorship}

Nil.

\section{Conflicts of interest}

There are no conflicts of interest.

\section{References}

1. Farrell TA, Wallace M, Hicks ME. Long-term results of transrenal ureteral occlusion with use of Gianturco coils and gelatin sponge pledgets. J Vasc Interv Radiol 1997; 8:449-52.

2. Asvadi NH, Arellano RS. Transrenal antegrade ureteral occlusion: Clinical assessment of indications, technique and outcomes. J Urol 2015;194:1428-32.

3. Saad WE, Kalagher S, Turba UC, Sabri SS, Park AW, Stone J, et al. Ureteric embolization for lower urinary tract fistulae: Use of two Amplatzer vascular plugs and N-butyl cyanoacrylate employing the "sandwich" technique. Cardiovasc Intervent Radiol 2013; 36:1068-72.

4. Huber T, Wilkins LR, Sabri S, Park AW, Stone JR, Angle JF, et al. Midterm follow-up of ureteral embolization using vascular plugs and N-butyl cyanoacrylate glue. J Vasc Interv Radiol 2017;28:1123-8. 